\title{
Experimental investigations of boron isotopic fractionation during incorporation into calcium carbonate
}

\author{
Ryuzo Ogawa ${ }^{1 *}$, Yusuke Fukami ${ }^{1}$, Takeshi Ohno ${ }^{1}$, \\ Katsuhiko Suzuki ${ }^{2}$ \\ ${ }^{1}$ Department of Chemistry, Gakushuin University, \\ Mejiro, Tokyo, Japan, 171-8588 \\ 2 Submarine Resources Research Center, JAMSTEC, \\ Natushima, Yokosuka, Kanagawa, Japan, 237-0061 \\ (*correspondence: w.j.kireek.25@outlook.jp)
}

The increase of atmospheric $\mathrm{CO}_{2}$ concentration affects the temperature rise of the earth's surface and the decrease of $\mathrm{pH}$ of seawater. Recently, the boron isotope ratio $\left({ }^{11} \mathrm{~B} /{ }^{10} \mathrm{~B}\right)$ in carbonates is considered to be a potential proxy of seawater $\mathrm{pH}$ [1]. Boron has two aqueous species in seawater: $\mathrm{B}(\mathrm{OH})_{3}$ and $\mathrm{B}(\mathrm{OH})_{4}^{-}$, and their relative abundances depend on the $\mathrm{pH}$ values. Moreover, boron isotopic fractionation occurs between two aqueous boron species, which leads to significant relationship between $\mathrm{pH}$ and boron isotopic fractionation. It has been often assumed that there is negligible isotopic fractionation during boron uptake in the carbonate. In this study, we determined the boron isotopic fractionation factor experimentally and evaluated the relationship between the crystal growth rate and boron isotopic fractionation.

Aragonites were synthesized under controlled $\mathrm{pH}$ conditions and we used solutions of $\mathrm{MgCl}_{2}-\mathrm{SrCl}_{2}-\mathrm{CaCl}_{2}-$ $\mathrm{B}(\mathrm{OH})_{3}-\mathrm{NaHCO}_{3}$ as the mother liquid. In this study, we evaluated rate constants of crystal growth rate from the decreasing calcium ion concentration per unit time, and the growth rate was controlled by varying saturation states $(\log \Omega=1.12-1.25)$. Concentrations of boron and calcium ion in samples were determined by ICP-MS, and boron isotope ratios were measured by MC-ICP-MS.

Under controlled $\mathrm{pH}$ condition ( $\mathrm{pH} 8.0$ ), the rate constants of crystal growth rate were varied from 0.036 to 0.071 by changing the degree of supersaturation $(\log \Omega=1.12-1.25)$. The $\delta^{11} \mathrm{~B}$ decrease with an increase of rate constants from 0.036 to 0.071 and the boron isotopic fractionation with difference crystal growth rates during precipitation is less than $2 \%$ (pH8.0), corresponding to $\mathrm{pH}$ change of 0.19 . In this presentation, the calculation method of boron isotopic fractionation between aqueous borate ion and boron species incorporated into the aragonite lattice will be discussed.

[1] Hemming and Hanson (1992) Geochim. Cosmochim. Acta 56, 537-543. 